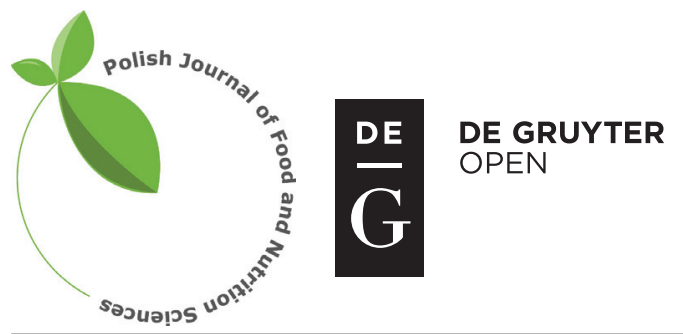

Pol. J. Food Nutr. Sci., 2017, Vol. 67, No. 3, pp. 183-190

DOI: $10.1515 /$ pjfns-2016-0025 http://journal.pan.olsztyn.pl

Original research article

Section: Food Technology

\title{
Characterization of Semolina Protein Film with Incorporated Zinc Oxide Nano Rod Intended for Food Packaging
}

\author{
Shima Jafarzadeh ${ }^{1 *}$, AbdKarim Alias ${ }^{2}$, Fazilah Ariffin ${ }^{3}$, Shahrom Mahmud ${ }^{4}$ \\ ${ }^{l}$ Food Biopolymer Research Group, Food Technology Division, School of Industrial Technology, \\ University Sains Malaysia, 11800 Minden,Penang,Malaysia, shimajafar@yahoo.com \\ ${ }^{2}$ Food Biopolymer Research Group, Food Technology Division, School of Industrial Technology, \\ University Sains Malaysia, 11800 Minden, Penang, Malaysia, akarim@usm.my \\ ${ }^{3}$ Food Biopolymer Research Group, Food Technology Division, School of Industrial Technology, \\ School of Industrial Technology, University Sains Malaysia, 11800 Minden, Penang, Malaysia, fazilah@usm.my \\ ${ }^{4}$ Nano Optoelectronic Research (NOR) Lab, School of Physics, \\ University Sains Malaysia, 11800 Minden, Penang, Malaysia, shahromx@usm.my
}

Key words: packaging, zinc oxide nanorods, UV absorbance, semolina

This study intended to provide biopolymer films used as food packaging, which will result in reducing environmental pollution produced by the activities of synthetic food packaging. We used zinc oxide nanorods ( $\mathrm{ZnO}-\mathrm{nr}$ ) and we prepared nanocomposite films by means of solvent casting. FTIR and SEM were employed to characterize the final films. SEM images revealed that $\mathrm{ZnO}$-nr particles were homogenously distributed throughout the film surface. The thermal, optical, and heat sealability properties of the films were also examined. Adding ZnO-nr significantly reduced oxygen permeability and heat sealability. The semolina films' UV absorbance was highly impacted by the degree of ZnO-nr addition. The nanocomposite films absorbed above $90 \%$ of the near infrared spectra. In addition, the zeta potential revealed the surface charge of $\mathrm{ZnO}$-nr had a negative charge of about $-33.9 \mathrm{mV}$.

\section{INTRODUCTION}

A large number of biodegradable polymers have been studied to develop edible films and finally lower the amount of waste produced through non-degradable petroleum-based food packaging activities [Tharanathan, 2003]. Not only do these edible films protect physically foods, they also prevent the mass transfer of aromas, oxygen, carbon dioxide, moisture, lipids, and flavors, into and from food products [Marcuzzo et al., 2010]. Considering nutritive merits and superior features, protein-based biopolymers have received considerable attention regarding the development of edible films [Gennadios, 2004]. These polymers are remarkable oxygen hurdles and they have certain mechanical properties to the films [Sothornvit et al., 2009].

Different types of proteins are used as components of biodegradable packaging [Khwaldia et al., 2010]. Of these proteins, the wheat protein is a potential constituent of packaging materials due to its expense effectiveness, renewability, biodegradability, and favorable film-forming and cohesive/adhesive features [Türe et al., 2013]. Semolina is considered as a type of wheat with flour rich in high gluten content [Quaglia, 1998;

\footnotetext{
* Corresponding Author: E-mail: shimajafar@yahoo.com (S. Jafarzadeh) infectious diseases via the antimicrobial impacts of $\mathrm{ZnO}$

Jafarzadeh et al., 2016]. The gluten strengthens the nutrient value of edible films. Semolina grain is highly hard, light colored, translucent, and displays antioxidant activities. Further, semolina extracts prevent radical-prompted liposome lipid peroxidation. They also show radical cation-scavenging performance [Onyeneho \& Hettiarachchy, 1992; Dufresne, 2006; Jafarzadeh et al., 2016].

Nevertheless, the poor water and mechanical sensitivity of biopolymers restrict their application in the activities of food packaging. Nanomaterials, which reinforce biopolymers through the formation of nanocomposites, have been recently employed to overcome these limitations [Petersson \& Oksman, 2006]. The nanoparticles used in the biopolymer matrix remarkably strengthen the physicochemical, thermal, optical properties of nanocomposites in comparison with pure biopolymer [Kovacevic et al., 2008] .

With respect to their enormous particular surface area and high energy of surface, nano-fillers display good interfacial relationship with polymer branches and as a result significantly promote polymer properties [Kumar \& Singh, 2008]. Zinc oxide ( $\mathrm{ZnO})$ has been broadly used as a functional filler in UV absorbers in cosmetics, pharmaceuticals, pigments and coating materials [Li et al., 2009; Li et al., 2010; Rajendra et al., 2010]. $\mathrm{ZnO}$ nanoparticle is able to potentially obstruct 
[Yu et al., 2004; Rajendra et al., 2010; Zhang et al., 2008]. The morphology, size, composition, crystallinity and shape of $\mathrm{ZnO}$ nanoparticles have an effect on their intrinsic properties [Lin et al., 2009; Shahrom \& Abdullah, 2007]. Lin et al. [2009] stated that $\mathrm{ZnO}$ nanorods ( $\mathrm{ZnO}-\mathrm{nr}$ ) display maximum UV-absorption performance.

Semolina has good properties for edible film production and $\mathrm{ZnO}$-nr are powerful materials in enhancing the physicochemical, thermal, and hurdles properties of semolina. In addition to these drawbacks, $\mathrm{ZnO}$-nr-reinforced semolina has not been widely understood. In the current study, we proposed that by adding $\mathrm{ZnO}$-nr with low-concentration into semolina films we can improve the thermal and barrier properties of films and that the final biopolymeric films display UV-blocking properties. With their desirable antioxidant activities, the suggested films could be utilized as food packaging particularly for cheese. The current study took advantage of $\mathrm{ZnO}$-nr as fillers to make semolina film bionanocomposites ready and described the physicochemical, morphology, thermal and barrier properties of the prepared films.

\section{MATERIALS AND METHODS}

\section{Materials}

Semolina flour (14.2\% protein, $18.5 \%$ gluten) was purchased from the local market in Tehran, Iran and then stored in a dry and cool place until the tests. Food-grade glycerol was obtained from SIM Company Sdn. Bhd. (Penang, Malaysia), whereas food-grade liquid sorbitol was purchased from LiangtracoSdn. Bhd. (Penang, Malaysia). The magnesium nitrate used to control humidity was purchased from Sigma Aldrich (Kuala Lumpur, Malaysia), and ZnO-nr was synthesized through the catalyst-free combust-oxidized mesh process as described by Shahrom \& Abdullah [2007].

\section{Preparation of bionanocomposite films}

Semolina flour $(4 \mathrm{~g})$ was dispersed by magnetic stirring in $80 \mathrm{~mL}$ of distilled water at room temperature, and the $\mathrm{pH}$ of the dispersion was adjusted to 8 with $1 \mathrm{~mol} \mathrm{NaOH}$. Similarly, various concentrations of $\mathrm{ZnO}$ powder $(1 \%, 2 \%, 3 \%, 4 \%$, and $5 \%$; w/w of total solid) and $2 \mathrm{~g}$ of a sorbitol and glycerol (3:1) mixture were dispersed in $20 \mathrm{~mL}$ of distilled water for 30 min followed by sonication in an ultrasonic bath (Marconi model, Unique USC 45 kHz, Piracicaba, Brazil). Subsequently, the dispersions of semolina flour and $\mathrm{ZnO}$-nr plasticizer were mixed and stirred at $90^{\circ} \mathrm{C}$ for $1 \mathrm{~h}$. For the preparation of nanocomposite films, the homogenous mixtures were poured into plates and the solvents were allowed to evaporate at room temperature for $24 \mathrm{~h}$.

The films were dried under controlled conditions in a humidity chamber $\left(25^{\circ} \mathrm{C}\right.$ and $58 \%$ relative humidity (RH). A control film was prepared in a similar manner except for the addition of nanoparticles. The dried films were peeled and stored at $23 \pm 2^{\circ} \mathrm{C}$ and $58 \% \mathrm{RH}$ until use.

\section{Oxygen permeability (OP)}

OP was determined using Mocon Oxtran 2/21 System (Minneapolis, MN, USA) at $25^{\circ} \mathrm{C}$ and $55 \pm 1 \%$ RH in accordance with the ASTM Standard Method D3985-05 [ASTM,
2005]. The films were placed on an aluminum foil mask that allowed an exposure area of $5 \mathrm{~cm}^{2}$. Three replicates of each film were evaluated.

\section{Heat seal strength measurement}

In order to seal the two parts of film samples together, an Impulse Auto Sealer was utilized (Mercier Corporation, ME-455A1, Taipei, Taiwan). The machine was also exploited in the manipulation of Pressure and Heat. The highest factor of heat seal was previously measured. This was done to enable us to generate the maximum seal strength in the used samples. With this regard, the specified heat seal temperature, dwell time, and pressure were kept at $110 \pm 5^{\circ} \mathrm{C}, 0.85 \mathrm{~s}$, and $1.8 \times 103 \mathrm{~Pa}$, respectively. In an attempt to inspect the needed tensile force in keeping the seal apart by the crosshead speed of $1 \mathrm{~mm} / \mathrm{s}$ and the preliminary distance of $25 \mathrm{~mm}$, we made use of TA XT Plus Texture Analyzer (Stable Micro System). Keeping at the angle of $180^{\circ}$, the peeled samples were attached at non-heat seal section. In order to gauge the strength of the seal (utmost seal/load length), the optimal load obtained was taken into consideration. The valuation of the peel seal was executed after $48 \mathrm{~h}$ of the heat sealing operation. The average value of the number of twelve samples, keeping in similar conditions, was determined. The calculation of the seal strength was obtained using the following method:

$$
\text { Seal strength }=\text { peak force } / \text { film width }
$$

Newton/meter $(\mathrm{N} / \mathrm{m})$ was stated for the seal strength to demonstrate the expected maximum force needed to trigger the seal to split.

\section{Fourier transform infrared spectroscopy (FT-IR)}

To determine the Fourier Transform Infrared Spectroscopy (FTIR) range of the designated films, FTIR spectrometer (Thermo Scientific, Madison, USA) was exploited by means of an attenuated total reflection (ATR) at the temperature of $25^{\circ} \mathrm{C}$. After placing the films onto the crystal cells, they were fixed into the FTIR spectrometer's mount. 32 scans at $4 \mathrm{~cm}^{-1}$ resolution were exploited in the process of collecting the $650-4000 \mathrm{~cm}^{-1}$ ranged spectra with automatic signal gain. They were also ratioed at the temperature of $25^{\circ} \mathrm{C}$ adjacent to a background spectrum which was recorded from the empty clean cell. The OPUS 3.0 (Bruker, Ettlingen, Germany) was employed as the data gathering programme for the purpose of analyzing the spectral data. The baseline correction and normalization of the spectra was carried out prior to the analysis of data.

\section{Optical properties}

We studied the absorbance of the films (in triplicate) at 200 and $800 \mathrm{~nm}$, by using the UV-vis spectrophotometer model UV-1650PC (Shimadzu, Tokyo, Japan). Biofilms were sectioned $(60 \mathrm{~mm} \times 4 \mathrm{~mm})$ and directly placed in a spectrophotometer test cell. An empty glass plate served as the reference.

\section{Decomposition temperature}

The samples $(\sim 15 \mathrm{mg})$ were scanned in a thermogravimetric analyzer (TGA-1, Perkin Elmer, Massachusetts, USA) 
from $40^{\circ} \mathrm{C}$ to $800^{\circ} \mathrm{C}$ at a rate of $10^{\circ} \mathrm{C} / \mathrm{min}$ in a nitrogen environment [Nuthong et al., 2009].

\section{Film morphology}

The conditioned bionanocomposite samples were vacuum coated with gold for field-emission scanning electron microscopy. The surface microstructure of the nanocomposite films was visualized using a Leo Supra 50 VP field-emission scanning electron microscope (Carl-Ziess. SMT, Oberkochen, Germany) equipped with an Oxford INCA 400 energy dispersive.

We used a Phillips CM12 transmission electron microscope. In addition, energy-dispersive X-ray spectroscopy (EDX) was conducted under $15 \mathrm{kV}$ incident electron energy.

\section{Zeta potential}

The zeta potential of $\mathrm{ZnO}-\mathrm{nr}$ was determined using Zeta sizer Nano-ZS90 (Malvern Instruments). The analysis was performed at a scattering angle of $90^{\circ}$ at a temperature of $25^{\circ} \mathrm{C}$ using samples diluted to different intensity concentration with deionized distilled water.

\section{Statistical analysis}

Experiments were performed in triplicate $(n=3)$ with three different lots of film samples and a completely randomized design (CRD) was used. ANOVA and Tukey's post-hoc tests were used to evaluate the mean values of the physical, barrier and thermal properties of the prepared semolina films at the 5\% significance level. Statistical analysis was conducted using SPSS version 22.0.

\section{RESULTS AND DISCUSSION}

\section{Oxygen permeability}

OP has been the most widely investigated transport property of edible polymer films. As a matter of fact, diverse factors influence the transport property of gases through polymer films. These properties include, according to Sanchez-Garcia et al. [2008], such properties as their path's tortuosity through the structure of the polymer; the extent to which they are exfoliated or dispersed; the properties of the filler in terms of the type, content, orientation and aspect ratio; the crystallinity of the induced filler; immobilization of polymer chain; and the propensity and retention of solvent in the induced filler. Various studies, for example Padua \& Wang [2002], Tharanathan [2003], and Hong \& Krochta [2003], have shown that due to the existence of polar interactions, an excellent OP properties can be observed in films which are produced from plant-based protein polymers.

The highest content of gluten can be found in semolina flour among the numerous types of protein-rich flours available. The formation of film is facilitated through the impartation of integrity due to the flexible and cohesive properties of gluten. Moreover, the main components of gluten are gliadins and glutenins which contain low-molecular-weight and high-molecular-weight proteins respectively. Accordingly, as maintained by Wittaya [2012], films are strengthened by high-purity gluten which in turn are useful barriers to oxygen.

As can be seen in Table 1, the increase in the content of $\mathrm{ZnO}$-nr significantly decreases the OP. The OP and bar-
TABLE 1. Permeability to oxygen of semolina nanocomposite films.

\begin{tabular}{l|c}
\hline ZnO-nr $(\% \mathrm{w} / \mathrm{w})$ & OP cc mil $/\left(\mathrm{m}^{2} \cdot\right.$ day $\left.\cdot \mathrm{atm}\right)$ \\
\hline Control & $2.04 \pm 0.04^{\mathrm{a}}$ \\
$1 \%$ & $1.13 \pm 0.02^{\mathrm{b}}$ \\
$2 \%$ & $1.01 \pm 0.03^{\mathrm{c}}$ \\
$3 \%$ & $0.90 \pm 0.02^{\mathrm{d}}$ \\
$4 \%$ & $0.82 \pm 0.02^{\mathrm{e}}$ \\
$5 \%$ & $0.71 \pm 0.10^{\mathrm{f}}$ \\
\hline
\end{tabular}

Different letters in each column represent significant difference among semolina films at the $5 \%$ level of probability

rier property are largely reduced and improved respectively, in the semolina film with $\mathrm{ZnO}-\mathrm{nr}(5 \%)$. A ca. 65\% reduction can be noticed in films containing $5 \% \mathrm{ZnO}$-nr. It is expected that for the diffusion of the oxygen molecules, a tortuous pathway is created by the nanoparticles fused into the matrix. It can also be argued that the reduction seen in the permeability coefficients can be interpreted as the passage of diffusing gases through this long path [Bourtoom \& Chinnan, 2008]. This is conversely in line with the finding of studies such as Bae et al. [2009] and Türe et al. [2013].

\section{Heat seal strength}

Heat sealability is a critical property of films used in packaging. Figure 1 shows the seal strengths of the nanocomposite films. The control films exhibited the strongest seal strength among all the films prepared. However, the seal strength weakened with increasing $\mathrm{ZnO}$-nr content. During sealing, two pieces of biofilms were inserted between two heated plates. We hypothesized that the nanoparticles in the protein polymer matrix possibly block the interaction between the two melted surfaces of the films during heat sealing. Our study revealed that the interactions occurring between the active groups of semolina were reduced by the nanoparticles inside the polymer matrix, which consequently weakened the seal strength of the bionanocomposite films; in addition, the reduced seal strength may be attributed to the reduction

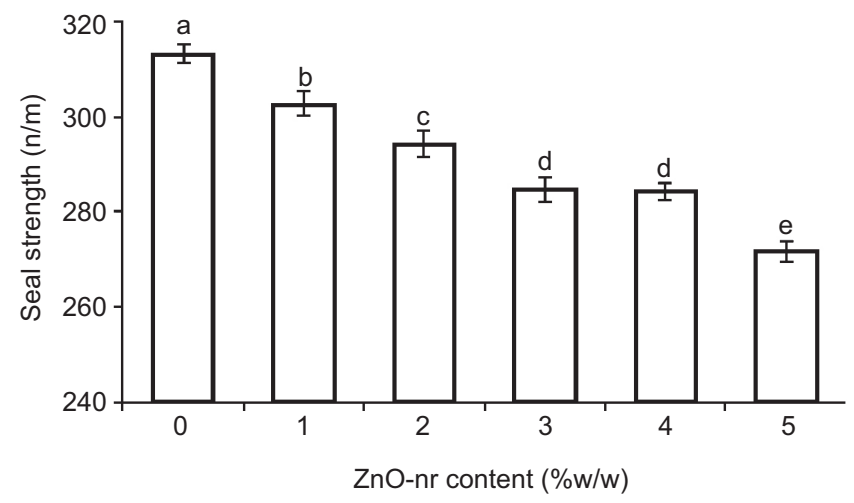

FIGURE 1. Effects of ZnO-nr contents on the heat sealability of semolina nanocomposite films. The bars indicate mean $(n=5) \pm$ SD. Different letters on the bars represent significant difference among the films at the $5 \%$ level of probability. 
TABLE 2. Light transmittance values of semolina films as affected by $\mathrm{ZnO}$-nr incorporation.

\begin{tabular}{|c|c|c|c|c|c|c|c|c|}
\hline \multirow{2}{*}{$\begin{array}{l}\mathrm{ZnO}-\mathrm{nr} \\
(\% \mathrm{w} / \mathrm{w})\end{array}$} & \multicolumn{8}{|c|}{ Light transmittance (\%) level } \\
\hline & 200 & 280 & 350 & 400 & 500 & 600 & 700 & 800 \\
\hline Control & 0 & 1.01 & 14.75 & 18.67 & 24.84 & 27.28 & 29.24 & 31.12 \\
\hline $1 \%$ & 0 & 0.33 & 3.479 & 3.955 & 10.413 & 16.602 & 22.29 & 27.368 \\
\hline $2 \%$ & 0 & 0.098 & 0.928 & 1.294 & 4.883 & 9.595 & 14.856 & 20.325 \\
\hline $3 \%$ & 0 & 0 & 0.061 & 0.366 & 1.367 & 2.905 & 5.139 & 7.959 \\
\hline $4 \%$ & 0 & 0 & 0.061 & 0.293 & 0.793 & 1.501 & 2.71 & 4.48 \\
\hline $5 \%$ & 0 & 0 & 0 & 0.146 & 0.439 & 0.671 & 1.038 & 1.66 \\
\hline
\end{tabular}

in the moisture content and flexibility of the films with increasing ZnO-nr content [Abdorreza et al., 2011]. Heat seal strength is usually used to evaluate the opening properties of the sealed package. High seal strength is desirable to realize tightly sealed food packaging, whereas low seal strength is suitable to obtain easy-open packaging.

\section{Optical properties}

In order to maintain the quality of food, the optical properties of biopolymer films are of highly significance in packaging food. This is due to the fact that light protection is of high priority when regarding the food quality.

According to Ramos et al. [2013], the UV barrier property of packaging films is desirable to prevent UV light-driven lipid oxidation, discoloration of packed food stuffs, and accordingly the nutrients shortfall. There are three zones identified for UV region: UVC (180-280 nm), UVB (280-320 nm), and UVA (320-400 nm). By means of a UV-vis spectrophotometer, the absorbance of biopolymer film properties and their nanocomposite were measured, the result of which can be seen in Figure 2 and Table 2. Not possessing nanoparticles, the semolina films as the control element exhibited an acceptable quality against $180-280 \mathrm{~nm}$ range UV. As discussed by Arfat et al. [2014], the existence of aromatic amino acids in high levels has resulted the protein based films to be commonly considered as great barriers against UV.

A clear peak of absorption was observed by nanocomposite films. An increase in the content of $\mathrm{ZnO}-\mathrm{nr}$ resulted in an increase in the peak of absorption. Semolina/ZnO-nr composite's absorption was at its peak at $380 \mathrm{~nm}$. The blue-shift phenomenon was clearly seen at these bionanocomposites' peak of absorption. Due to the effect of quantum confinement, the $\mathrm{ZnO}$-nr would increase, the result of which is the emission of $\mathrm{ZnO}-\mathrm{nr}$ biocomposites and accordingly the blue shift phenomenon [Subramani et al., 2007]. CMC/ZnO nanocomposite films revealed the similar results as well [Yu et al., 2009].

\section{FTIR analysis}

The vibration properties of synthesized materials can be noticeably examined through the usage of FTIR spectroscopy. The properties that influence the absorption peak and band positions are the structure, the chemical composition as well as morphology of thin films. There are four regions viewed for FTIR spectroscopy which extends between: 1) ranges from 4,000 to $2,500,2$ ) ranges from 2,500 to 2,000 , 3) ranges from 2,000 to 1,500 and 4) ranges from 1, 500 to 400. In condition of a peak of 4,000 to 2,500 for the spectrum, a consistency of peak with absorption can be noticed stimulated by $\mathrm{C}-\mathrm{H}, \mathrm{O}-\mathrm{H}$ and $\mathrm{N}-\mathrm{H}$ single bonds.

Alternatively, a peak of spectrum ranging from 2,500 to 2,000 , the consistency can be observed for the peak with triple-bond induced absorption. This agreement would be observed with double bond absorption, including $\mathrm{C}=\mathrm{N}$, $\mathrm{C}=\mathrm{O}$ and $\mathrm{C}=\mathrm{C}$, when the spectrum peak ranges from 2,000 to 1,500. The semolina-based FT-IR spectra and the semolina nanocomposite films are presented in Figure 3. Ranging from

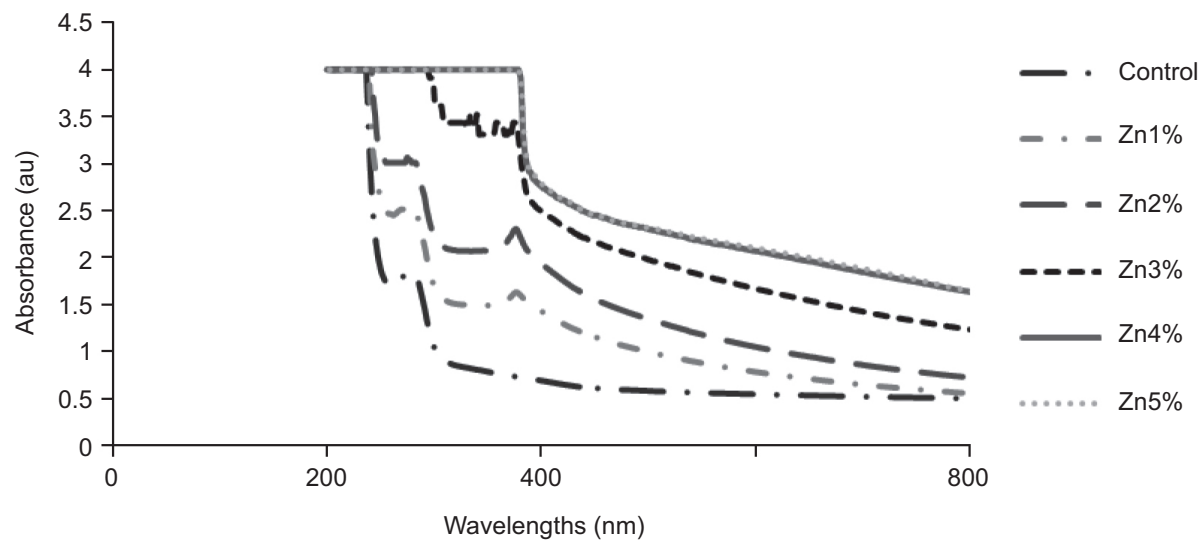

FIGURE 2. UV-vis absorbance of semolina nanocomposite films at $25^{\circ} \mathrm{C}$. 


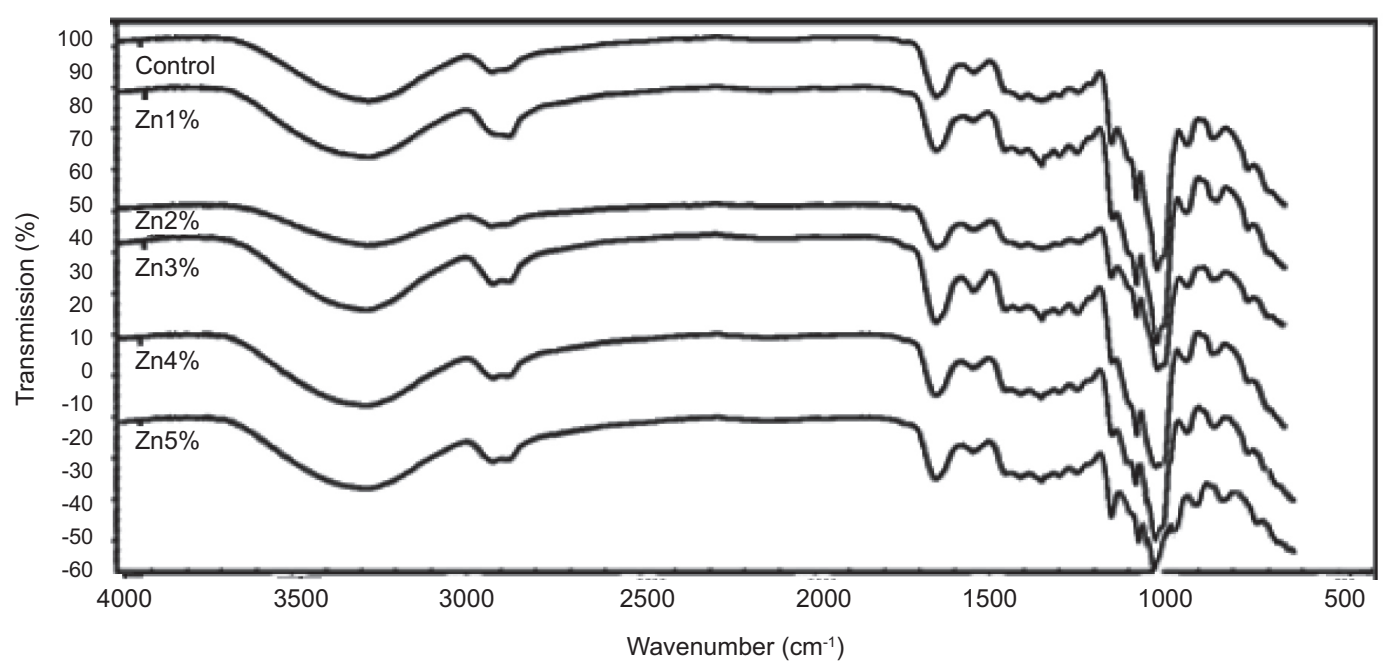

FIGURE 3. FT-IR transmittance spectra of semolina nanocomposite films at $25^{\circ} \mathrm{C}$.

$3287 \mathrm{~cm}^{-1}$ to $664 \mathrm{~cm}^{-1}$, different properties of the peaks were shown for the spectrum of nano-composite film. The peaks of absorption ranging from 400 to $700 \mathrm{~cm}^{-1}$ could be ascribed to stretching modes of all $\mathrm{ZnO}$ samples [Djaja et al., 2013]. The vibration of $\mathrm{ZnO}$ at $664 \mathrm{~cm}^{-1}$ was the determinant factor for the peak of absorption in the present research. There was found no new functional group after the fusion of nanocomposite, which could be perceived as a physical contact between nanocomposite and film matrix.

\section{Scanning electron microscopy (SEM), EDX and TEM}

SEM is the most widely applied technique to characterize the shape, size, morphology, and porosity of matrices. Figure 4 shows the SEM images and EDX spectra of the semolina films and $\mathrm{ZnO}$-nr-reinforced films. TEM also revealed that the nanorods were cylindrical with hexagonal cross section (Figure 4). The control film exhibited a smooth and compact surface morphology, whereas the nanocomposite films showed a slightly rough surface. SEM images revealed that
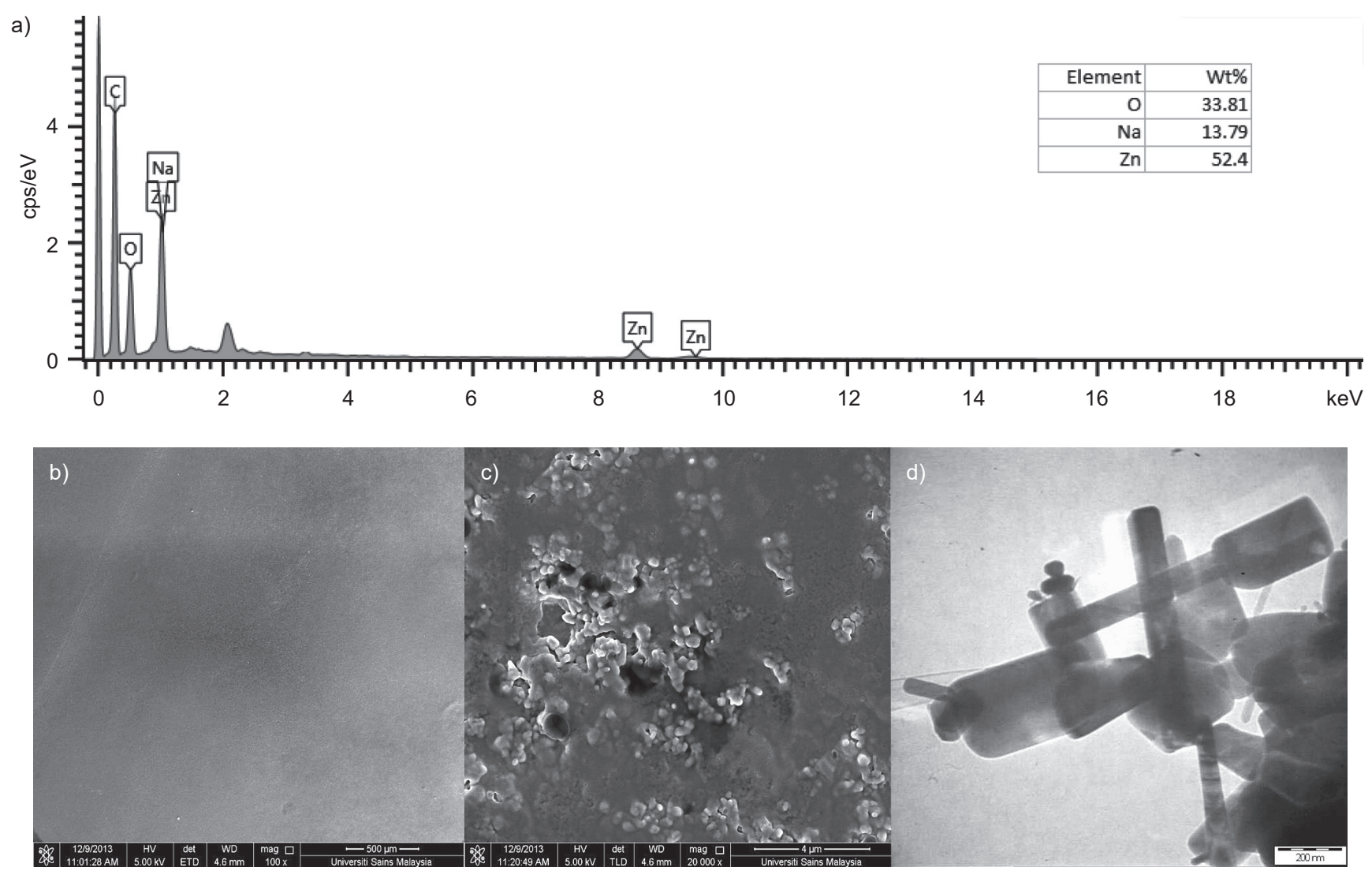

FIGURE 4. (a) EDX spectrum, (b)FESEM micrograph of pure semolina film surface, and (c) ZnO-nr-reinforced semolina film surface, (d) TEM micrograph of $\mathrm{ZnO}-\mathrm{nr}$. 


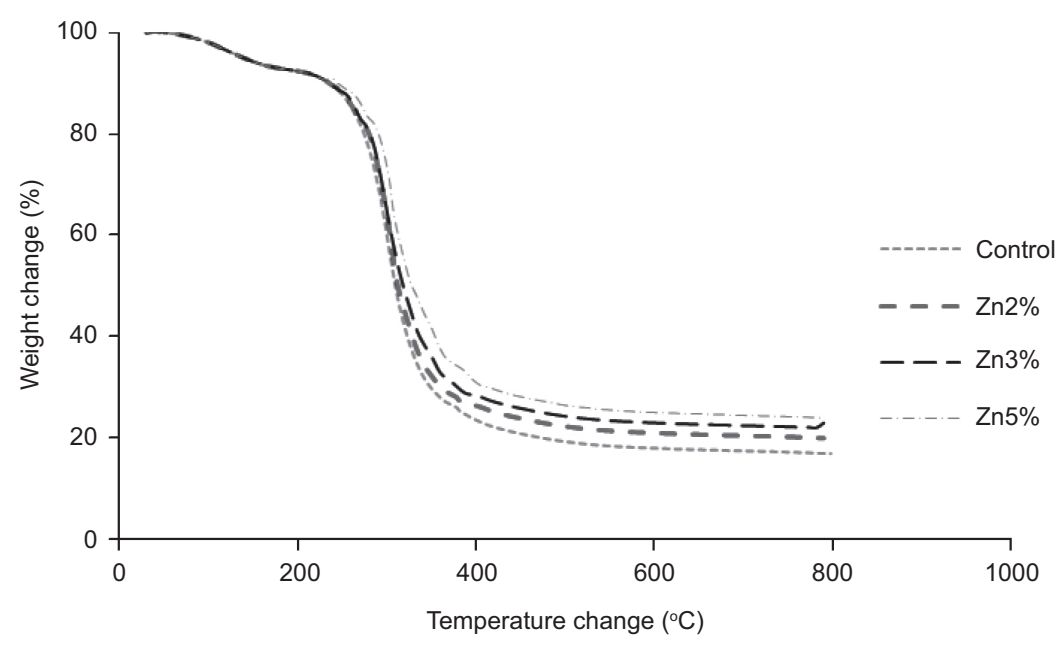

FIGURE 5. Decomposition curves of semolina films compared with ZnO-nr-reinforced films.

ZnO-nr particles were homogenously distributed throughout the film surface, which possibly rendered the surface of the nanocomposite films rough. This finding is possibly associated with the protruded film structures resulting from the increased thickness of the films. Figure 4 illustrates the EDX spectrum of semolina/ $\mathrm{ZnO}$-nr films. If $\mathrm{ZnO}$-nr content was increased, their signals could be detected. As shown in Figure 4, C, Zn, O and Na elements were identified.

\section{TGA}

The control biopolymer's thermal stability and the associated nanocomposite films are displayed in Figure 5. Considering semolina and $\mathrm{ZnO}$-nr-reinforced films, a slight variation in the temperature of decomposition was discovered by using TGA thermogram. As can be seen in Figure 5, there is approximately $18 \%, 22 \%$ and $5 \%$ of residue for the control and the $\mathrm{ZnO}$-nr-reinforced film. Nevertheless, the divergence in the temperature of films decomposition was insignificant, which could be the result of an insignificant volume of the added nanoparticles. However, contrary to this finding, the study by Zou \& Yoshida [2010] indicates an increase in the temperature of polymeric films decomposition and difference in the volume of nitrogen residue by adding nanoparticle.

\section{Zeta potential-surface charge}

The stability of particle in suspension has a great influence on the surface charge or Zeta potential which is done through the electrostatic repulsion among particles. In other words, the higher repulsion between particles would lead to a higher Zeta potential. A surface charge is possessed by nanoparticles through which a thin layer of opposite charge ions is attracted to the surface of the nanoparticle. As the solution causes this double layer of ions to diffuse with the nanoparticle to diffuse, it moves with the nanoparticle. The particles' Zeta potential is the electric potential placed at the edge of the double layer. This electric potential normally has the volume between $+100 \mathrm{mV}$ to $-100 \mathrm{mV}$. As can be observed in Figure 6, a negative charge of approximately $-33.9 \mathrm{mV}$ can be valued for $\mathrm{ZnO}-\mathrm{nr}$ surface. Higher measures of stability can also be detected for nanoparticles with Zeta Potential of the values higher than $+25 \mathrm{mV}$ or smaller than $-25 \mathrm{mV}$.

\section{CONCLUSIONS}

The present research characterized and created semolinabased nanobiocomposites of $\mathrm{ZnO}$-nr for food packaging purposes. There are some reasons why semolina was employed as

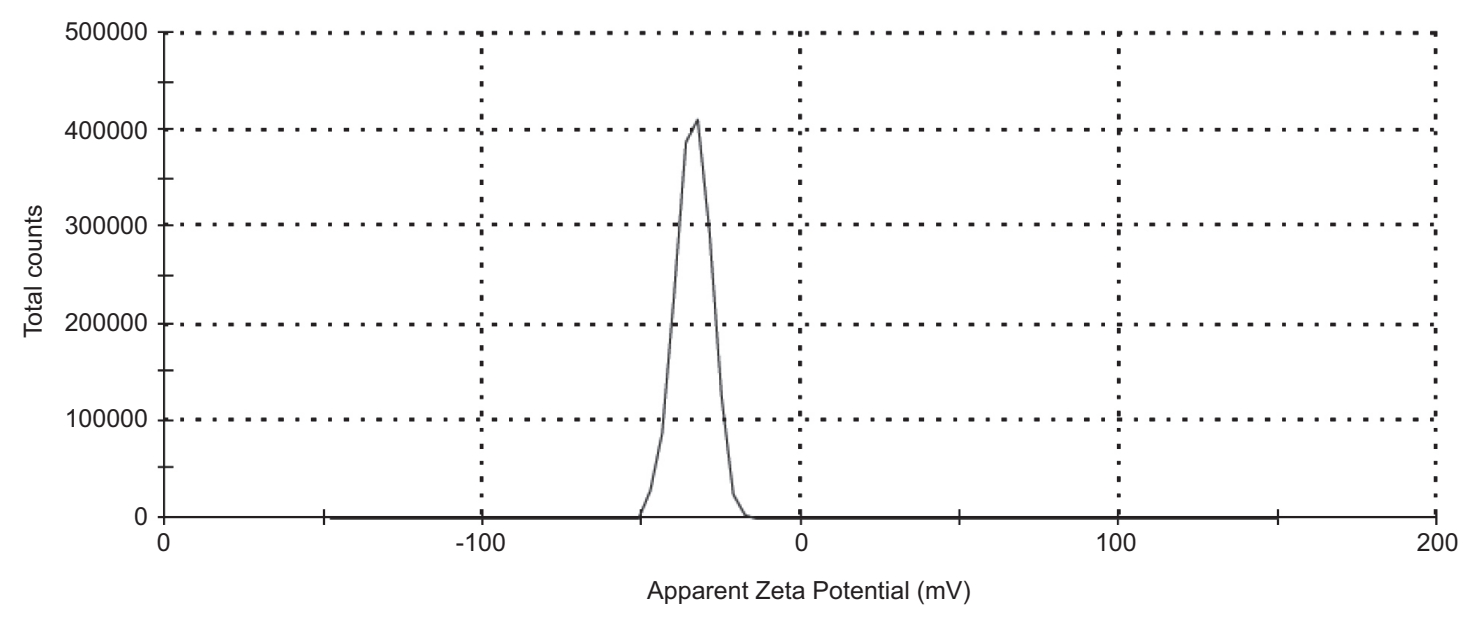

FIGURE 6. Zeta potential of ZnO-nr. 
a polymeric matrix including its great accessibility in nature, biodegradability, low expenditure, and great gluten content, which enhance the biopolymer films' nutritional properties.

$\mathrm{ZnO}-\mathrm{nr}$ played a crucial role in improving the physical properties of semolina-based biocomposites. Having incorporated low degree of $\mathrm{ZnO}-\mathrm{nr}$ fillers, important differences were witnessed in the film properties, especially in barrier and UV support activities. The optical property of bionanocomposites showed that the nanocomposite films had absorbed above $90 \%$ of the near infrared spectra via adding small degree of $\mathrm{ZnO}-\mathrm{nr}$ to the biopolymer matrix. The Zeta potential test showed that the surface charge of $\mathrm{ZnO}-\mathrm{nr}$ was $-33.9 \mathrm{mV}$, and that the higher the surface charge was the higher was the repulsion and dispersion between particles. The FTIR spectra displayed the physical relationship between $\mathrm{ZnO}-\mathrm{nr}$ and the semolina. The crystal facets also maximized the UV absorption. The present findings stressed that the biopolymer-based nanocomposite films are environment friendly in films packaging to make an improvement in the shelf life of food as well as viable replacement to petroleum-based or synthetic packaging films. Overall, this study suggests that semolina films incorporated with $\mathrm{ZnO}-\mathrm{nr}$ show a strong potential to be used as active films.

\section{RESEARCH FUNDING}

The authors acknowledge the University Sains Malaysia for supporting this project (GOT grant number 1001/ PFIZIK/823130).

\section{CONFLICT OF INTEREST}

Author declare no conflict of interest.

\section{REFERENCES}

1. Abdorreza M.N., Cheng L.H., Karim A.A., Effects of plasticizers on thermal properties and heat sealability of sago starch films. Food Hydrocolloid., 2011, 25, 56-60.

2. Arfat Y.A., Benjakul S., Prodpran T., Sumpavapol P., Songtipya P., Properties and antimicrobial activity of fish protein isolate/ fish skin gelatin film containing basil leaf essential oil and zinc oxide nanoparticles. Food Hydrocolloid., 2014, 41, 265-273.

3. ASTM., Annual Book of ASTM Standards. 2005, Philadelphia, PA.

4. ASTM., Standard Test Method for Seal Strength of Flexible Barrier MaterialsF88/F88M-09, Philadelphia, PA, 2009, Annual book of ASTM Standards.

5. Bae H.J., Park H.J., Hong S.I., Byun Y.J., Darby D.O., Kimmel R.M., Whiteside W.S., Effect of clay content, homogenization $\mathrm{RPM}, \mathrm{pH}$, and ultrasonication on mechanical and barrier properties of fish gelatin/montmorillonite nanocomposite films. LWT - Food Sci. Technol., 2009, 42, 1179-1186.

6. Bourtoom T., Chinnan M.S., Preparation and properties of rice starch-chitosan blend biodegradable film. LWT - Food Sci. Technol., 2008, 41, 1633-1641.

7. Djaja N. F., Montja D. A., Saleh R., The effect of Co incorporation into Zno nanoparticles. Adv. Material. Physc. Chem., 2013, 3, 33-41.
8. Dufresne A., Comparing the mechanical properties of high performances polymer nanocomposites from biological sources. J. Nano Sci. Nano Techno., 2006, 6, 322-330.

9. Gennadios A., Edible films and coatings from proteins. 2004, in: Proteins in Food Processing (ed. R. Yada). Wood Head Publishing, Cambridge, UK, pp. 467-489.

10. Hong S.I., Krochta J.M., Oxygen barrier properties of whey protein isolate coatings on polypropylene films. J. Food Sci., 2003, 68, 224-228.

11. Jafarzadeh S., Alias A.K., Ariffin F., Mahmud S., Najafi A., Preparation and characterization of bionanocomposite films reinforced with nano kaolin. J. Food Sci. Technol., 2016, 53, 1111-1119.

12. Khwaldia K., Arab Tehrany E., Desobry S., Biopolymer coatings on paper packaging materials. Compreh. Rev. Food Sci. Food Safety, 2010, 9, 82-91.

13. Kovacevic E., Stefanovic I., Berndt J., Godde C., Winter J., Boufendi L., The nanoparticle formation in hydrocarbon plasmas. Publ. Astronom. Observ. Belgrade, 2008, 84, 151-152

14. Kumar A.P., Singh R.P., Biocomposites of cellulose reinforced starch: Improvement of properties by photo-induced crosslinking. Biores. Technol., 2008, 99, 8803-8809.

15. Li J.H., Hong R.Y., Li M.Y., Li H.Z., Zheng Y., Ding J., Effects of $\mathrm{ZnO}$ nanoparticles on the mechanical and antibacterial properties of polyurethane coatings. Prog. Org. Coat., 2009, 64, 504-509.

16. Li X.H., Xing Y.G., Li W.L., Jiang Y.H., Ding Y.L., Antibacterial and physical properties of poly (vinyl chloride)-based film coated with $\mathrm{ZnO}$ nanoparticles. Food Sci. Technol. Int., 2010, 16, 225-232.

17. Lin O.H., Akil H.M., Mahmud S. Effect of particle morphology on the properties of nanoZnO/polypropylene composites. Adv. Compos Lett., 2009, 18, 77-83.

18. Mahmud S., Abdullah M.J., Tapered head of Zinc Oxide nanorods. Solid State Sci. Technol., 2007, 15, 1, 108-115.

19. Marcuzzo E., Sensidoni A., Debeaufort F., Voilley A., Encapsulation of aroma compounds in biopolymeric emulsion based edible films to control flavour release. Carbohydr. Polym., 2010, 80, 984-988.

20. Nuthong P., Benjakul S., Prodpran T., Characterization of porcine plasma protein-based films as affected by pretreatment and cross-linking agents. Int. J. Biol. Macromol., 2009, 44, 143-148.

21. Onyeneho S.N., Hettiarachchy N.S., Antioxidant activity of durum wheat bran. J. Agr. Food Chem., 1992, 40, 1496-1500.

22. Padua G.W., Wang Q., Formation and properties of corn zein films and coatings. 2002, in: Protein Based Films and Coatings (ed. A. Gennadios). CRC Press, USA, pp. 43-68.

23. Petersson L., Oksman K., Biopolymer based nanocomposites: comparing layered silicates and microcrystalline cellulose as nanoreinforcement. Compos. Sci. Technol., 2006, 66, 2187-2196.

24. Quaglia G.B., Other durum wheat products. 1988, in: Durum Chemistry and Technology (eds. M.J. Sissones, J. Abecassis, B. Marchylo, M. Carcea). AACC International, St. Paul, M.N., pp. 263-282.

25. Rajendran R., Balakumar C., Ahammed H.A.M., Jayakumar S., Vaideki K., Rajesh E., Use of zinc oxide nano particles for production of antimicrobial textiles. Int. J. Eng. Sci. Technol., 2010, 2, 202-208. 
26. Ramos Ó.L., Reinas I., Silva S.I., Fernandes J.C., Cerqueira M.A., Pereira R.N., Vicente A.A., Poças M.F., Pintado M.E., Malcata F.X., Effect of whey protein purity and glycerol content upon physical properties of edible films manufactured there from. Food Hydrocolloid., 2013, 30(1), 110-122.

27. Sanchez-Garcia M.D., Gimenez E., Lagaron J.M., Morphology and barrier properties of solvent cast composites of thermoplastic biopolymers and purified cellulose fibers. Carbohydr. Polym., 2008, 71, 235-244.

28. Sothornvit R., Rhim J.W., Hong S.I. Effect of nano-clay type on the physical and antimicrobial properties of whey protein isolate/ clay composite films. J. Food Eng., 2009, 91,468 473.

29. Subramani C., Mhaske S.T., Kathe A.A., Varadarajan P.V., Prasad V., Vignesh-Waran N., Functional behaviour of polypropylene/ZnO-soluble starch nanocomposites. Nanotechnology, 2007, 18(38), 385702.

30. Tharanathan R.N., Biodegradable films and composite coatings: past, present and future. Trends Food Sci. Technol., 2003, 14, 71-78.

31. Türe H., Gällstedt M., Johansson E., Hedenqvist M.S., Wheat-gluten/montmorillonite clay multilayer-coated paperboards with high barrier properties. Ind. Crop Prod., 2013, 51, 1-6.
32. Wittaya T., Protein-based edible films: characteristics and improvement of properties. 2012, in: Structure and Foundation of Food Engineering (ed. A.A. Eissa). InTech, Rijeka, Croatia, pp. 43-70.

33. Yu D., Cai R., Liu Z., Studies on the photo degradation of Rhodamine dyes on nanometer-sized zinc oxide. Spectrochim Acta A., 2004, 60, 1617-1624.

34. Yu J., Yang J., Liu B., Ma X., Preparation and characterization of glycerol plasticized-pea starch/ZnO-carboxymethylcellulose sodium nanocomposites. Biores. Technol., 2009, 100, 2832-2841 .

35. Zhang L., Ding Y., Povey M., York D., ZnO nanofluids-A potential antibacterial agent. Prog. Nat. Sci. Mat. Int., 2008, 18(8), 939-944

36. Zou D.Q., Yoshida H., Size effect of silica nanoparticles on thermal decomposition of PMMA. J. Therm. Anal. Calorim., 2010, 99, 21-26.

Submitted: 27 February 2016. Revised: 17 July, 24 July and 5 September 2016. Accepted 12 September 2016. Published on-line: 19 January 2017. 